\title{
OBTENCIÓN DE EMBRIONES SOMÁTICOS PRIMARIOS DE Theobroma cacao EN CLONES DE INTERÉS REGIONAL PARA EL DEPARTAMENTO NORTE DE SANTANDER, COLOMBIA.
}

Por:

Luz Stella Monsalve González, Claudia Yanet García Rojas, ${ }^{2}$ Alina K. Sigarroa Rieche ${ }^{3}$

\section{RESUMEN}

La Embriogénesis Somática es la formación de un embrión a partir de una célula somática. (23) Este método de regeneración se reconoce en todo el mundo como el más eficiente para la micropropagación de especies vegetales, permitiendo obtener grandes cantidades de material de siembra, lo cual es una necesidad en el país para la renovación de plantaciones de Theobroma cacao. Este trabajo busca una alternativa de solución, pues se evalúan las condiciones óptimas para establecer embriones somáticos primarios en 4 genotipos de interés regional (THS-565, ICS-95, CCN-51 y IMC-67). Fueron evaluados dos medios de cultivo, dos condiciones ambientales y dos tipos de explantes. Para los cuatro genotipos en estudio, los mayores valores de inducción a formación de callo embriogénico se presentó en los medios que contenían 2,4D -TDZ como balance hormonal y glucosa como fuente de carbono. Los Estaminoides presentan una mejor formación de callo, sin embargo, en Petaloides se obtienen mayor número de embriones somáticos y mejor desarrollo de los mismos. La combinación Kinetina-2,4 D favorece la Embriogénesis Somática de baja frecuencia para ICS95, IMC-67, TSH-565; mientras que el clon CCN-51 se favorece en medio con 6BAP-2,4D. Los resultados mostraron una alta dependencia del genotipo, por lo cual las condiciones ambientales, los balances hormonales y la frecuencia embriogénica son diferentes para cada uno de los clones, siendo ICS-95 y IMC67 los que mejor comportamiento presentaron, y TSH 565 y CCN-51 tuvieron una menor respuesta en los tratamientos evaluados.
Palabras claves: Theobroma cacao, Embriogénesis Somática, Thidiazurón TDZ, Clones élites.

\section{ABSTRACT}

The somatic Embryogenesis is the formation of an embryo from a somatic cell. (23) This method of regeneration is recognized anywhere in the world like most efficient for the micropropagation of vegetal species, allowing to obtain great amounts of sowing material, which is a necessity in the country for the renovation of plantations of Theobroma cacao. This job looks for a solution alternative, because the optimal conditions are evaluated to establish primary somatic embryos in 4 genotypes of regional interest (THS-565, ICS-95, CCN-51 and IMC-67). Two environmental conditions, two means of culture, and two types of explantes were evaluated. For the four genotypes in study, the greater values of induction to formation of embryogenic callus appeared in the means that contained 2,4D - TDZ like hormonal balance and glucose like carbon source. The Estaminoides presents one better formation of callus, nevertheless, in Petaloides they obtain greater number of somatic embryos and better development of such. The combination Kinetina-2,4 D favors the Somatic Embryogenic of Low frequency for ICS-95, IMC-67, TSH-565; where as clone CCN-51 is favored in the middle with 6BAP-2,4D. The results showed a high dependency of the genotype, thus the environmental conditions, the hormonal balance and the embryogenic frequency is different for each one from the clones, being ICS-95 and IMC-67 those that better behavior presented, and TSH 565 and CCN-51 had a smaller answer in the evaluated treatments.

Key Words: Theobroma cacao, Somatic Embryogenesis, Thidiazuron TDZ, Elitist Clons.

\footnotetext{
${ }^{1}$ Ingeniero de Producción Biotecnológica - Auxiliar Laboratorio Biotecnología Vegetal U.F.P.S. - luzsmg@yahoo.es

2 Ingeniero de Producción Biotecnológica - Asistente Laboratorio Biología Molecular - garciacaya@yahoo.com

${ }^{3}$ Ingeniero Agrónomo - Docente U.F.P.S. - aksigarr@bari.ufps.edu.co; asigarroa@yahoo.com
} 
Obtención de embriones somáticos primarios de Theobroma cacao en clones de interés regional para el Departamento Norte de Santander, Colombia.

\section{INTRODUCCIÓN}

Theobroma cacao es un cultivo de gran importancia para los países tropicales y el Cacao que de él se obtiene cuenta con gran aceptación y considerable demanda a nivel mundial. En Colombia tiene una gran importancia por su influencia socio-económica, ya que es el sustento de 25'000 familias campesinas en el país. En el 2003 Colombia ocupó a nivel mundial el $11^{\circ}$ puesto como productor con $47.000 \mathrm{Tm}$, y a nivel nacional, Norte de Santander aparece en $3^{\circ}$ lugar con el $7.5 \%$ de la producción total, formando parte de la región cacaotera del país. (1)

En Colombia el cultivo presenta un bajo rendimiento (0.47 Tm/ $\mathrm{Ha})$, ocasionado fundamentalmente por la heterogeneidad y vejez de las plantaciones, requiriéndose la renovación de las mismas en aproximadamente un 75 - $80 \%$ del área cultivada. Para dar respuesta a esta demanda es necesario producir abundante material de siembra. (19)

La Biotecnología, ofrece nuevas alternativas a esta problemática nacional. Las técnicas de propagación "in vitro", son una herramienta importante para producir abundante material de siembra libre de enfermedades, con alta uniformidad genética.

Estudios realizados por Orchard et al, 1979, y Passey et al 1983, demostraron que la regeneración vía organogénesis presenta grandes problemas para Theobroma cacao, debido a yemas recalcitrantes y poco desarrollo de raíz pivotante. $(15,16)$ Posteriormente Esan y Pence, 1979, realizaron los primeros estudios en Embriogénesis Somática utilizando embriones cigóticos inmaduros como fuente de explantes (4); similares trabajos fueron reportados por Litz, 1986, utilizando hojas jóvenes (12), Sondahl, 1993, con flores inmaduras (21) y Figueira, 1993 a partir de tejido nuclear (7); estos autores reportaron bajo porcentaje de conversión en plantas. En recientes publicaciones realizadas en conjunto por investigadores del Instituto LE CIRAD Francia (Alemano et al, 1997), y la Universidad Pennsylavania U.S.A. (Li et al, 1998), han establecido protocolos eficientes de E.S en cacao a partir de explantes florales, aplicable a una amplia variedad de genotipos de cacao de interés para los cultivos de África $(2,11)$. Maximova et al 2002 optimizaron el proceso de embriogénesis secundaria a partir de embriones somáticos primarios y su conversión en planta. (13). Actualmente, vitroplantas obtenidas por este método se encuentran establecidas en campo en Santa Lucia (Brasil) y en África. En Ecuador, Garzón et al, 2004, aplicaron la metodología desarrollada por Li et al (1998), modificada por Maximova et al (2002), en 42 genotipos de cacao tipo Nacional, los cuales mostraron altos niveles de reactividad callogénica y embriogénica; aunque se presentó gran diferencia entre la respuesta de los genotipos. (8)

Esta investigación tuvo como objetivo general, estudiar las condiciones óptimas de trabajo en la obtención de embriones somáticos primarios de clones de Theobroma cacao de interés regional.

\section{MATERIALES Y METODOS}

El trabajo se desarrolló en las instalaciones del Complejo Biotecnológico de la Universidad Francisco de Paula Santander, ubicado en la sede de Campos Eliseos, municipio de Los Patios, Norte de Santander. La investigación es la primera etapa de un macroproyecto que busca obtener altos volúmenes de material vegetal de siembra para la renovación del cultivo de cacao en la región.

Los experimentos se realizaron con 4 clones de interés regional: CCN-51, ICS-95, IMC-67 y TSH-565, escogidos por sus características de productividad, adaptabilidad y tolerancia a enfermedades.

En el montaje se empleó un diseño factorial completamente aleatorizado, con manipulación de variables como medio de cultivo (concentraciones hormonales y fuente de carbono), condiciones ambientales de incubación y dos tipos de explantes, factores fundamentales en el desarrollo de la Embriogénesis Somática Primaria. 
Obtención de embriones somáticos primarios de Theobroma cacao en clones de interés regional para el Departamento Norte de Santander, Colombia.

Material de siembra. La zona de recolección fue en el municipio de Cúcuta, corregimiento de Agua Clara, Instituto Agrícola Jorge Gaitán Durán. El material vegetal recolectado fueron flores inmaduras, de las cuales se extraen los tipos de explantes estudiados: Petaloides y Estaminoides.

Desinfección. Se llevó a cabo la rutina utilizando lavado con agua corriente, inmersión en alcohol al $70 \%$ y como desinfectante Hipoclorito de sodio al $2 \%$, durante 15 minutos.

Etapa 1. Inducción y formación de callo embriogénico. Se trabajó con dos variantes de medio de cultivo DKW 100\% tal y como se describe en el Cuadro 1, además se evaluaron dos condiciones ambientales de incubación: fotoperíodo de 16 horas luz (días largos) y completa oscuridad, en cada tipo de explante, dando un total de 8 tratamientos por genotipo estudiado. Se efectuaron evaluaciones semanales y los parámetros evaluados fueron: fenolización, formación y tipo de callo.

Cuadro 1. Medios de cultivo para inducción

\begin{tabular}{|l|l|l|l|}
\hline \multirow{2}{*}{$\begin{array}{l}\text { Nombre } \\
\text { Medio }\end{array}$} & \multicolumn{2}{|c|}{$\begin{array}{c}\text { Concentración Hormonal } \\
\text { (en mg/l) }\end{array}$} & \multicolumn{1}{|c|}{$\begin{array}{c}\text { Fuente de } \\
\text { Carbono }\end{array}$} \\
\cline { 2 - 3 } & $2,4 \mathrm{D}$ & \multicolumn{1}{|c|}{ TDZ } & \\
\hline CEP1 & 2 & 0.005 & Glucosa \\
\hline CEP2 & 2 & 0 & Sacarosa \\
\hline
\end{tabular}

Etapa 2. Desarrollo embriogénico. Se evaluó la incidencia de 2 citoquininas (KIN - 6BAP) en este proceso, para lo cual se trabajó con dos variantes de medio de cultivo Lloyd and Mc Cown's 100\% + 2,4 D en rango de 1-3 mg/l (Cuadro 2). Se continuó evaluando las dos condiciones ambientales de incubación: fotoperíodo de $16 \mathrm{~h} \mathrm{luz} \mathrm{y} 8 \mathrm{~h}$ oscuridad (días largos) y completa oscuridad, en cada tipo de explante, dando un total de 8 tratamientos por genotipo estudiado. En esta etapa se valoró la contaminación, fenolización, formación de callo, tipo de callo, frecuencia embriogénica, tamaño de los embriones y su estado.
Cuadro 2. Medios de cultivo para Proliferación

\begin{tabular}{|l|l|l|}
\hline \multirow{2}{*}{$\begin{array}{l}\text { Nombre } \\
\text { Medio }\end{array}$} & \multicolumn{2}{|c|}{$\begin{array}{c}\text { Concentración Hormonal } \\
\text { (en mg/l) }\end{array}$} \\
\cline { 2 - 3 } & Kinetina & 6 BAP \\
\hline CE3 & 0.3 & 0 \\
\hline CE4 & 0 & 0.06 \\
\hline
\end{tabular}

Procesamiento de datos. Los análisis estadísticos se elaboraron, utilizando los métodos de Análisis de Varianza (ANOVA) y la comparación múltiple de medias por el Test de Duncan para las variables cuantitativas y para las variables cualitativas se hizo una distribución de frecuencia.

\section{RESULTADOS Y DISCUSIONES}

En la Etapa 1, el objetivo es inducir en los explantes la expresión embriogénica, la cual se comprueba con la formación de callos embriogénicos en la etapa siguiente. En el Cuadro 3 pueden observarse por cada clon, los resultados para la variable formación de callo en los diferentes tratamientos.

Cuadro 3. Comparación de medias y probabilidad de ocurrencia real de la variable formación de Callo, Etapa 1.

\begin{tabular}{|lc|c|c|c|}
\hline \multicolumn{1}{|c|}{ Tratamiento } & CCN-51 & ICS-95 & IMC-67 & TSH-565 \\
\hline 1.CEP1-Luz-Petaloides & $3.40^{\text {abc }}$ & $1.90^{\mathrm{a}}$ & $2.40^{\mathrm{a}}$ & $0.50^{\mathrm{a}}$ \\
\hline 2. CEP1-Luz-Estaminoides & $\underline{\mathbf{6 . 2 0}}^{\mathrm{c}}$ & $2.80^{\mathrm{a}}$ & $\underline{\mathbf{2 . 5 0}}^{\mathrm{a}}$ & $\mathbf{2 . 1 0}^{\mathrm{ab}}$ \\
\hline 3. CEP1-Osc.-Petaloides & $2.80^{\mathrm{abc}}$ & $\mathbf{3 . 7 0}^{\mathrm{a}}$ & $1.60^{\mathrm{a}}$ & $1.20^{\mathrm{ab}}$ \\
\hline 4. CEP1-Osc.-Estaminoides & $\mathbf{5 . 3 0}^{\mathrm{bc}}$ & $\mathbf{4 . 4 0}^{\mathrm{a}}$ & $\mathbf{2 . 4 0}^{\mathrm{a}}$ & $\underline{\mathbf{3 . 2 0}}^{\mathrm{b}}$ \\
\hline \hline 5. CEP2-Luz-Petaloides & $1.00^{\mathrm{a}}$ & $2.60^{\mathrm{a}}$ & $1.10^{\mathrm{a}}$ & $0.40^{\mathrm{a}}$ \\
\hline 6. CEP2-Luz-Estaminoides & $3.20^{\mathrm{abc}}$ & $2.70^{\mathrm{a}}$ & $1.80^{\mathrm{a}}$ & $0.40^{\mathrm{a}}$ \\
\hline 7. CEP2-Osc.-Petaloides & $2.30^{\mathrm{ab}}$ & $1.80^{\mathrm{a}}$ & $1.50^{\mathrm{a}}$ & $0.00^{\mathrm{a}}$ \\
\hline 8. CEP2-Osc.-Estaminoides & $3.90^{\mathrm{abc}}$ & $3.40^{\mathrm{a}}$ & $1.50^{\mathrm{a}}$ & $0.50^{\mathrm{a}}$ \\
\hline $\begin{array}{c}\text { Probabilidad de Ocurrencia } \\
\text { Real }\end{array}$ & $\mathbf{9 9 . 0} \%$ & $\mathbf{3 2 . 0} \%$ & $\mathbf{5 . 4 0} \%$ & $\mathbf{9 8 . 6} \%$ \\
\hline \begin{tabular}{c} 
Pea \\
\hline
\end{tabular}
\end{tabular}

* Letras desiguales indican diferencias significativas entre tratamientos al nivel $\propto=0.01$, según Test Duncan.

** Los valores en negrita subrayado indican el tratamiento con mejor respuesta y solo negrita indica el segundo mejor tratamiento.

El Clon CCN-51 presentó la mayor formación de callo con valores que oscilaban entre $10-62 \%$ de explantes, y el de más bajo resultado fue el TSH-565 con valores entre el 0 y $32 \%$; los clones ICS-95 y IMC-67 presentaron un comportamiento intermedio. 
Obtención de embriones somáticos primarios de Theobroma cacao en clones de interés regional para el Departamento Norte de Santander, Colombia.

Los clones CCN-51 y TSH-565, presentaron diferencias significativas entre tratamientos, siendo el medio CEP1 (Suplementado con TDZ y Glucosa) en condiciones de luz el más apropiado para obtener tejido calloso en CCN-51, mientras que el clon TSH-565, se comportó mejor en el mismo medio pero en condiciones de oscuridad. Se observó que este clon presenta altos índices de fenolización; es bien sabido que el proceso de fenolización afecta el establecimiento de los tejidos vegetales "in vitro", el cultivo en completa oscuridad puede ayudar a controlar el proceso de oxidación de fenoles, por ello los clones que tienen más contenido fenólico muestran mejores respuestas cuando son sometidos a oscuridad total. Adicionalmente, en la mayoría de los reportes se puede encontrar que hay mejor formación de callo en oscuridad porque se reduce la oxidación de las auxinas que juegan un papel importante en la formación de estas estructuras. (18)

Para los clones ICS-95 y IMC-67, no se presentaron diferencias significativas para ninguna de las variables evaluadas. Esto es debido a que las diferencias observadas de las medias y varianza fueron mínimas, el experimento fue demasiado insensible para detectar la diferencia en el nivel de probabilidad real deseado, del 99\%; sin embargo, pude apreciarse que los mejores resultados se obtuvieron también con el Medio 1 en condiciones de luz para el clon IMC-67 y en oscuridad para el ICS-95.

En general podemos observar que para todos los clones el mejor medio fue el CEP-1, que contenía TDZ y Glucosa, con valores desde 5 - $62 \%$ dependiendo del clon; mientras que en el medio CEP-2, los valores estuvieron entre 0-39\%. La adición de bajas concentraciones de TDZ al medio de cultivo, (0.005 $\mathrm{mg} / \mathrm{L}$ ), siempre favoreció la formación y apariencia del callo (callo friable).

Estos resultados concuerdan con los obtenidos por la Universidad de Pennsylvania, producto de las investigaciones realizadas por Li, Z., A. Traore, S.
Maximova, and M. J. Guiltinan sobre la Embriogénesis Somática y regeneración de plantas a partir de explantes florales de cacao. $(5,9,10)$. Según sus estudios las bajas concentraciones de TDZ usadas en esta etapa afectan positivamente el crecimiento del callo, la frecuencia de Embriogénesis y el número de embriones somáticos producidos por cada explante sensible. (1 1)

La acción del TDZ como inductor en este proceso fue señalada por Murthy et al, (1998), el autor califica a esta hormona como mediador de la inducción en la regeneración celular y reporta que el mecanismo de acción del TDZ aun no es claro, pero se ha registrado que actúa como sustituto de citoquininas y auxinas, requeridas para la organogénesis y Embriogénesis Somática en algunas especies, efectuando un crecimiento y diferenciación del tejido del explante. Varios informes indican que puede actuar a través de la modulación de los reguladores endógenos de crecimiento como resultado del estrés inducido, y la modificación en las membranas celulares. (14)

Los Estaminoides siempre mostraron mejor formación de callo que los Petaloides, esto puede deberse a la naturaleza de las células que los conforman, ya que en el cojin floral los estaminoides se encuentran fundidos en la base con los estambres y cerca de la zona meristemática floral, su parte basal es un área pequeña menor que la de los Petaloides, a medida de que las células se alejan de la zona meristemática adquieren gradualmente un estado de diferenciación. Al momento de la siembra, la mayor parte de la superficie del estaminoide queda en contacto con el medio debido a su estructura recta y alargada, a diferencia de los petaloides que tienen una curva en forma de cuello de cisne entre la capucha y la lígula, que le dificulta un mayor contacto con el medio. Por lo anterior, los estaminoides pueden ser un tejido más apto para la formación de callo, producido por una división mitótica temprana y la desdiferenciación de las células somáticas. 
Obtención de embriones somáticos primarios de Theobroma cacao en clones de interés regional para el Departamento Norte de Santander, Colombia.

Podemos decir que al menos un tratamiento tiene efectos reales y no por casualidad, por tanto se afirma que la respuesta embriogénica está fuertemente influenciada por el genotipo. Roca (1991) afirma que la respuesta embriogénica depende del genotipo de la planta; algunas variedades se pueden regenerar fácilmente en un medio específico, mientras que otras de la misma especie no responden en el mismo medio. (20)

En la Etapa 2, se busca el desarrollo de callo embriogénico y la formación de embriones en estado globular, ambos objetivos se lograron pero en diferentes grados según el genotipo.

Los resultados del Análisis de Varianza (ANOVA), no mostraron diferencias significativas para ninguno de los cuatro clones estudiados en ninguna de las variables evaluadas. En la variable formación de callos, se demostró que los estaminoides tuvieron la mejor respuesta, con un comportamiento similar a la etapa anterior para todos los clones (Ver Figura 1).

Figura 1. Formación de callo en estaminoide. Textura friable. Clon ICS-95 Etapa 2.

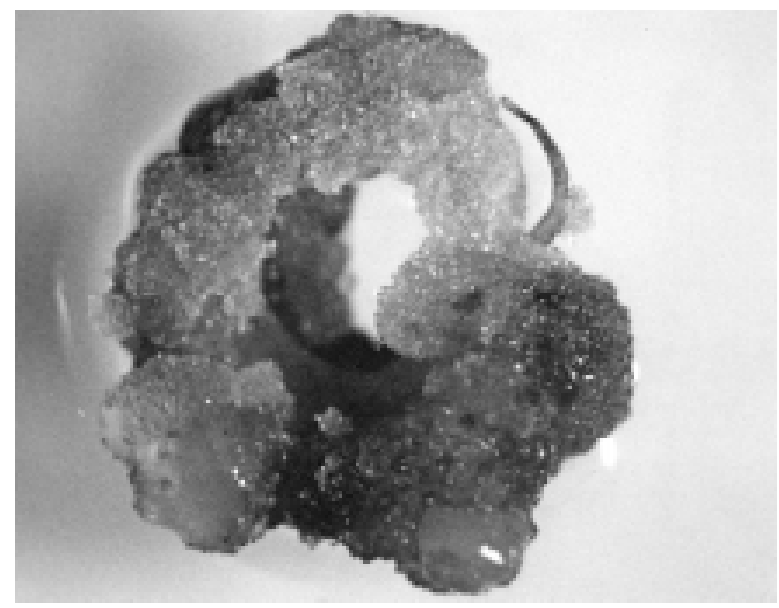

Con relación a la respuesta embriogénica (\# callos con embriones, \# Embriones por callo y el tamaño de los embriones), como se muestra en el Cuadro 4, el clon CCN-51 presentó un comportamiento opuesto a los otros clones, siendo su mejor respuesta del $16 \%$ en los estaminoides cultivados en el medio con balance hormonal 6BAP-2.4D en condiciones de oscuridad; contrario a los otros clones donde la mejor respuesta se dio en el medio con balance hormonal Kinetina2.4D, con el tipo de explante Petaloides. La diferencia en el comportamiento del CCN - 51, se ve reflejado en los bajos porcentajes de ocurrencia real.

Cuadro 4. Comparación de Medias y probabilidad de ocurrencia Real de la variable Formación de Callo, etapa 1.

\begin{tabular}{|c|c|c|c|c|c|c|c|c|}
\hline \multirow[t]{2}{*}{ Tratamiento } & \multicolumn{2}{|c|}{ CCN-51 } & \multicolumn{2}{|c|}{ ICS-95 } & \multicolumn{2}{|c|}{ IMC-67 } & \multicolumn{2}{|c|}{ TSH-565 } \\
\hline & $1^{*}$ & $2^{* *}$ & 1 & 2 & 1 & 2 & 1 & 2 \\
\hline 1.CE3-Luz-Petaloides & $0.1^{\mathrm{a}}$ & $0.6^{\mathrm{a}}$ & $0.28^{\mathrm{a}}$ & $0.28^{\mathrm{a}}$ & $2.0^{\mathrm{a}}$ & $1.75^{\mathrm{a}}$ & $0.2^{\mathrm{a}}$ & $1.2^{\mathrm{a}}$ \\
\hline 2. CE3-L & $0.4^{\mathrm{a}}$ & $1.0^{\mathrm{a}}$ & $0.08^{\mathrm{a}}$ & $0.14^{\mathrm{a}}$ & $1.0^{\mathrm{a}}$ & $0.25^{\mathrm{a}}$ & $0.1^{\mathrm{a}}$ & $0.1^{\mathrm{a}}$ \\
\hline 3. CE3-Osc.-Petaloides & $0.4^{\mathrm{a}}$ & $0.8^{\mathrm{a}}$ & $\underline{0.8}^{\mathrm{a}}$ & $\underline{0.8}^{\mathrm{a}}$ & $1.5^{\mathrm{a}}$ & $\underline{2.2}^{\mathrm{a}}$ & $0.4^{\mathrm{a}}$ & $0.8^{\mathrm{a}}$ \\
\hline 4. CE3-Osc.-Estaminoides & $0.3^{\mathrm{a}}$ & $0.9^{\mathrm{a}}$ & $0.5^{\mathrm{a}}$ & $0.5^{\mathrm{a}}$ & $1.9^{\mathrm{a}}$ & $0.9^{\mathrm{a}}$ & $0.6^{\mathrm{a}}$ & $0.4^{\mathrm{a}}$ \\
\hline 5. CE4-Luz-Petaloides & $0.3^{\mathrm{a}}$ & $0.8^{\mathrm{a}}$ & $0.16^{\mathrm{a}}$ & $0.16^{\mathrm{a}}$ & $0.5^{\mathrm{a}}$ & $0.5^{\mathrm{a}}$ & $0.0^{\mathrm{a}}$ & $0.0^{\mathrm{a}}$ \\
\hline 6. CE4-Luz-Estaminoides & $0.4^{\mathrm{a}}$ & $0.9^{\mathrm{a}}$ & $0.16^{\mathrm{a}}$ & $0.33^{\mathrm{a}}$ & $0.0^{\mathrm{a}}$ & $0.75^{\mathrm{a}}$ & $0.3^{\mathrm{a}}$ & $0.2^{\mathrm{a}}$ \\
\hline 7. CE4-Osc.-Petaloides & $0.3^{\mathrm{a}}$ & $0.2^{\mathrm{a}}$ & $0.0^{\mathrm{a}}$ & $0.0^{\mathrm{a}}$ & $1.1^{\mathrm{a}}$ & $0.80^{\mathrm{a}}$ & $0.1^{\mathrm{a}}$ & $0.1^{\mathrm{a}}$ \\
\hline 8. CE4-Osc.-Estaminoides & $0.6^{\mathrm{a}}$ & $1.6^{\mathrm{a}}$ & $0.14^{\mathrm{a}}$ & $0.14^{\mathrm{a}}$ & $0.7^{\mathrm{a}}$ & $0.30^{\mathrm{a}}$ & $0.1^{\mathrm{a}}$ & $0.1^{\mathrm{a}}$ \\
\hline $\begin{array}{c}\text { \% Probabilidad de Ocurrencia } \\
\text { Real }\end{array}$ & 12.6 & 13.2 & 77.6 & 81.3 & 51.4 & 78.9 & 69.6 & 67.4 \\
\hline
\end{tabular}

* 1: \#callos con embriones

** 2: \# embriones por callo

En el Cuadro 5, se aprecia que el clon CCN-51, presentó el porcentaje más alto de callo tipo medio (12.5\%) y el más bajo porcentaje en callo tipo friable $(30.9 \%)$ con respecto a los otros clones; y con el mayor porcentaje de fenolización en grado 2 (15.4\%), factores que pudieron afectar su respuesta embriogénica. Pérez (1998), dice que el callo puede tener diferentes apariencias y color en dependencia de la especie o genotipo con que se trabaje, así como las condiciones del cultivo "in vitro". (18)

Al respecto, Bajai (1995), define que los tipos de callo que se pueden presentar en un proceso de regeneración indirecta pueden ser: friables, medio y acuoso. El friable es globular, nodular de apariencia seca, color blanquecino muy denso, este tipo de callo da como resultado la formación de masas pro embriogénicas debido a las divisiones que se presentan en las capas de células de los callos, esto puede marcar el comienzo de la embriogénesis somática. Se puede afirmar que el tipo de callo friable es el recomendado para un óptimo desarrollo embriogénico. (3) 
Obtención de embriones somáticos primarios de Theobroma cacao en clones de interés regional para el Departamento Norte de Santander, Colombia.

Cuadro 5. Comparación de porcentajes totales de las variables cualitativas Etapa 2

\begin{tabular}{|l|c|c|c|r|r|r|r|r|}
\hline \multirow{2}{*}{ CLONES } & \multicolumn{3}{|c|}{ FENOLLZACIÓN } & \multicolumn{2}{c|}{ CALLO } & \multicolumn{3}{|c|}{ TEXTURA CALLO } \\
\cline { 2 - 9 } & 0 & 1 & 2 & \multicolumn{1}{|c|}{ Ausencia } & Presencia & Ligero & Friable & Medio \\
\hline CCN-51 & 30.9 & 53.7 & 15.4 & 47.7 & 52.3 & 8.9 & 30.9 & 12.5 \\
\hline ICS-95 & 9.2 & 90.8 & 0.0 & 54.8 & 45.2 & 7.3 & 34.7 & 3.2 \\
\hline IMC-67 & 54.5 & 40.5 & 5.0 & 49.6 & 50.4 & 8.3 & 39.1 & 3.0 \\
\hline TSH-565 & 50.6 & 46.8 & 2.6 & 59.87 & 40.13 & 9.65 & 30.14 & 0.34 \\
\hline
\end{tabular}

Como se muestra en la Figura 2, el clon IMC-67 tuvo un precoz desarrollo embriogénico hasta estado corazón y con alta frecuencia embriogénica en el tratamiento Kinetina Oscuridad petaloides, donde la media de \# embriones por callo (22\%), es mayor que el \# callos con embriones (15\%) y los embriones formados en estado globular tenían un tamaño promedio de $16 \mathrm{~mm}$.

Figura 2. Formación de embriones estado globular en petaloides. Clon IMC-67 Tratamiento Kinetina Oscuridad. La flecha muestra un embrión iniciando estado corazón.

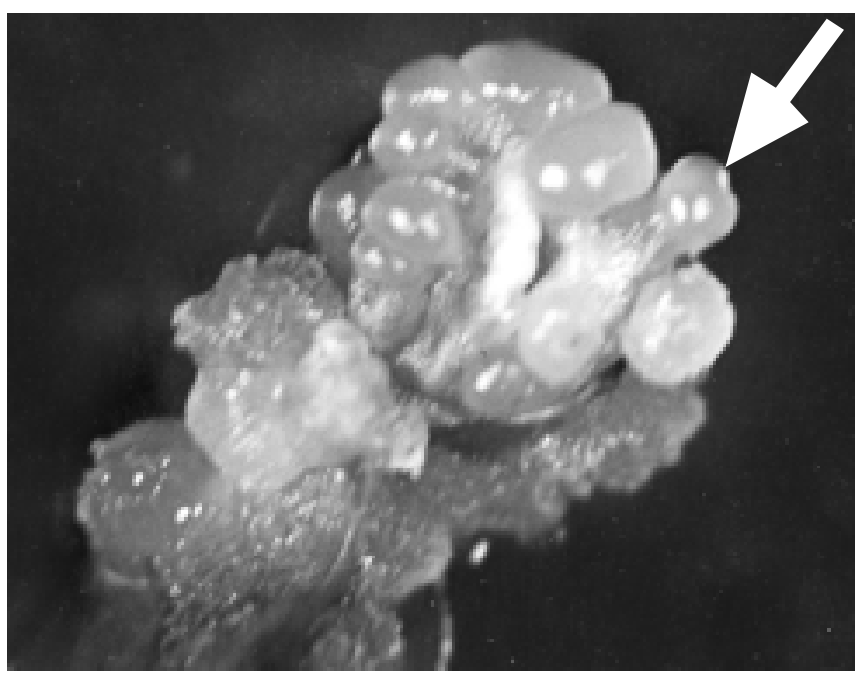

En cuanto al medio de cultivo, se afirma que el medio que contenía balance Hormonal de 7 partes de 2,4 D (2,4 - diclorofenoxiacético) por 1 parte de Kinetina (6-furfuril adenina), dio mejor resultado en un rango del $1-22 \%$ dependiendo del genotipo, comparado con el medio con balance hormonal de 40 partes de 2,4-D por 1 parte de 6BAP (6-Bencil- aminopurina) en el que se obtuvo resultados del $0-16 \%$, para las variables en estudio como se observa en el Cuadro 4.
Al respecto, Taiz et al (1998), afirma que la respuesta de los tejidos a la adición externa de reguladores de crecimiento, pueden ser el resultado de la interacción con contenidos endógenos de otros reguladores presentes en el tejido vegetal, y en algunos casos, las respuestas están dadas por dos o mas reguladores o un regulador que induce la síntesis de otro. (22). En el experimento se vio la importancia en esta etapa de la adición de citoquininas en altas concentraciones, siendo más favorable la Kinetina que el 6 BAP.

El papel de las citoquininas en el medio primario o inductor del embrión es menos claro, aun que normalmente este medio incluye una de ellas. Se dice que su acción radica en que derivan de la adenina, por lo cual se pueden unir a la cromatina del núcleo, tienen un efecto promotor sobre el ARN y las enzimas, actúan en la traducción del ARN e incrementan la rapidez de síntesis de proteínas. (20)

Existe un papel sinérgico entre ambos reguladores, la acción de una citoquinina en presencia de una auxina estimula estados tempranos de diferenciación celular. La citoquinina incrementa la sensibilidad del tejido al estímulo de la auxina y este incremento de sensibilidad favorece la diferenciación celular. Ambos reguladores participan en la dinámica del ciclo celular, importante en el proceso de diferenciación y posterior desarrollo de embriones somáticos. Las citoquininas estimulan la división celular en los tejidos junto a concentraciones óptimas de auxina. (17)

La adición de auxinas exógenas puede producir un aumento sustancial de los niveles de AIA endógenos, se ha demostrado que estas altas concentraciones están asociadas con el incremento de la respuesta embriogénica en varias especies. De Vries et al., (1988), plantea que la presencia de la auxina en los tejidos induce alteraciones en el pH del citoplasma y la pared celular, y Además, provoca varias divisiones asimétricas al alterar la polaridad de las células, lo cual llevará a la formación del estado globular de los embriones. (17) 
Obtención de embriones somáticos primarios de Theobroma cacao en clones de interés regional para el Departamento Norte de Santander, Colombia.

\section{CONCLUSIONES}

Los cuatros clones en estudio mostraron respuesta embriogénica en diferentes grados, por lo que puede afirmarse la alta dependencia del genotipo en el proceso. Los clones CCN-51 y TSH-565 presentaron las menores respuestas, el clon IMC-67 tuvo buenos resultados aunque no en la misma proporción del clon ICS-95, el cual presentó el mayor desarrollo embriogénico.

El comportamiento del clon CCN-51, en la inducción de callo fue mejor en estaminoides cultivados en Glucosa - TDZ, bajo un fotoperíodo de 16 Horas Luz; seguidamente en la Etapa 2 la mayor respuesta en la formación de embriones se presentó en los estaminoides cultivados en el medio 2.4D- 6BAP en oscuridad total.

El comportamiento del clon ICS-95, en la inducción de callo fue mejor en los estaminoides cultivados en Glucosa - TDZ, bajo oscuridad total; consecutivamente el desarrollo embriogénico fue superior en los petaloides cultivados en el medio con 2.4-D - KIN bajo condiciones de oscuridad.

El comportamiento del clon IMC-67, en la inducción de callo fue mejor en los estaminoides cultivados en Glucosa - TDZ, independiente de las condiciones ambientales; posteriormente el desarrollo embriogénico fue mayor en los petaloides cultivados en el medio con 2.4D- KIN independiente de las condiciones ambientales.

Para el clon TSH-565, la inducción de callo fue mejor al usar estaminoides cultivados en Glucosa - TDZ, bajo oscuridad total; seguidamente la formación de pro embriones fue superior en los petaloides cultivados en el medio con 2.4D- KIN en condiciones ambientales de luz.

En todos los clones los estaminoides son los explantes con mejor respuesta para la proliferación de callo friable, pero una vez formados los callos, los petaloides son más aptos para la formación de embriones somáticos primarios.

La presencia del TDZ en la etapa inductora es necesaria para todos lo clones estudiados.

El balance Hormonal 2,4 D (2,4 - diclorofenoxiacético) y Kinetina (6-furfuril adenina), dio el mejor resultado para el desarrollo de estructuras pro embriogénicas por encima de la combinación 2,4-D y 6BAP (6-Bencilaminopurina).

\section{RECOMENDACIONES}

Realizar nuevos experimentos para optimizar el proceso, determinando el tiempo de exposición, y secuencia hormonal (citoquininas) para los clones TSH-565, IMC-67 y CCN-51.

Estudiar las siguientes etapas del proceso de embriogénesis somática primaria, la maduración, germinación y posterior conversión en planta de los embriones somáticos primarios obtenidos en esta investigación.

Se deben realizar estudios de embriogénesis somática secundaria para aumentar la productividad del proceso, evaluando los estaminoides como explante primario, por su potencial callogénico.

Estudiar la variabilidad genética que se puede presentar en el proceso de Embriogénesis Somática.

Realizar estudios histológicos para corroborar la independencia vascular del embrión con el tejido materno.

\section{AGRADECIMIENTOS}

Al Fondo de Investigaciones Universitarias (FINU)U.F.P.S., por el apoyo financiero. 
Obtención de embriones somáticos primarios de Theobroma cacao en clones de interés regional para el Departamento Norte de Santander, Colombia.

A FEDECACAO-Norte de Santander por su asesoramiento en campo.

Al Instituto Agrícola Jorge Gaitán Durán ubicado en el corregimiento de Aguaclara, por permitir el acceso del material vegetal.

\section{BIBLIOGRAFÍA}

1.AGROCADENAS - Observatorio de Agrocadenas. Descripción de la cadena del Cacao [on line] Bogota 2004.Disponible en Internet: www.agrocadenas.gov.co/cacao.

2.ALEMANNO, L.; BERTHOULY, M.; MICHAUXFERRIE'RE, N. A comparison between Theobroma cacao L. zygotic embryogenesis and somatic embryogenesis from floral explants. En: In Vitro Cell Dev. Biol. Plant V. 33; 1997. p. 163-172.

3.BAJAJ, Y.P.S Biotehnology in Agriculture and Forestry 30. Somatic Embryogenesis and Synthetic Seed I. New Delhi: s.n., 1995. p. $72-85$.

4.Esan, E. B. Pence Tissue culture studies on T. cacao. 5th int. Cacao Rest. Conf. Nigeria. 1975.

5.ESTADOS UNIDOS. COPYRIGHT THE PENSILVANIA STATE UNIVERSITY. Cacao Tissue Culture Protocol Book, Version 1.3. Pennsylvania: United States Department of Agriculture, December 8, 2000.

6.FEHÉR, Attila, PASTERNAK and DUDITS, Dénes. Transition of somatic plant cell to an embryogenic state. En: Plant cell tissue and organ culture. V. 74, 2003. p. 201-228.

7.FIGUEIRA, A.; JANICK, J. Development of nucellar somatic embryos of Theobroma cacao. En: Acta Hort. V. 336, 1993. p.231-238.
8.GARZÓN, I., CASTILLO, B., CEDEÑO, M. Y ALEMANNO, L. Respuesta de clones seleccionados de cacao de la variedad Nacional a la cacao de la variedad Nacional a la multiplicación in vitro vía Embriogénesis Somática en Ecuador. V Encuentro Latinoamericano y del Caribe de Biotecnología Agrícola. República Dominicana. s.l.: s.n., 2004.

9.GUILTINAN, M., et el. Method and tissue culture media for inducing somatic Embryogenesis and efficient regeneration of plant cacao. United States Patent. 6.150.587. 2000.

10. . Laboratory Plant Biotechnology and Molecular biology of cacao [on line]. Pennsylvania, 2004. Internet: htpp//:guiltinanlab.cas.psu.edu

11.LI, Z., A. TRAORE, S. MAXIMOVA, AND M. J. GUILTINAN. Somatic embryogenesis and plant regeneration from floral explants of cacao (Theobroma cacao L.) using thidiazuron. En: In vitro Cell. Dev. Biology Plant. 1998.

12.LITZ, R. E. Tissue Culture Studies with T. cacao. En: Cacao Biotechnology Symposium. Pennsylvania State University. U.S.A: s.n., 1986.

13.MAXIMOVA, S. N, L. ALEMANNO, A. YOUNG, A. TRAORE, N. FERRIER, AND M. J. GUILTINAN. Genotypic Variability, Efficiency and Cellular Origin of Primary and Secondary Somatic Embryogenesis of Theobroma cacao L., The Chocolate Tree. En: In Vitro Cell. Dev. Biol._Plant 38. s.I.: s.n., 2002. p.252-259.

14.MURTHY, S. J., MURCH, S.J., SAXENA, P.K. Review: Thidiazuron: Un regulador potente de la morfogénesis in vitro de la planta. En: Cell. In vitro Dev Biol. Plant V. 34. 1998. p. 267-275.

15.ORCHARD, J. E.; Colin, H. y Hardwick, K. Culture of shoot apices of Theobroma cacao. En: Physiol. Plant. s.I.: s.n., 1979. p.47, $207-210$. 
Obtención de embriones somáticos primarios de Theobroma cacao en clones de interés regional para el Departamento Norte de Santander, Colombia.

16.PASSEY et al. Shoot proliferation in rooting in vitro of T. cacao L. type melonado. Journal Hortic. Sci. 1983.

17.PASTERMAK, T, PRINSEN, E, DUDITS, D AND FEHÉR, A. The role of auxin, $\mathrm{pH}$ and stress in the activation of embriogenic cell division yn leaf protoplast derived cells of alfalfa. En: Plant Physiol. s.l.:s.n, V. 129. 2002. p. 1807-1819.

18.PÉREZ PONCE, J. N., et al. Propagación y mejora genética de plantas por biotecnología. Cuba: Instituto de Biotecnología de las plantas, 1998. p. 57-65.

19.RAMIREZ DAVILA, Ciro Alfonso. Diagnóstico regional del cultivo de Cacao. Cúcuta: FEDECACAO Seccional Norte de Santander, 2004.

20.ROCA, William. Cultivo de tejidos en la agricultura. Cali: CIAT, 1991. p. 147-151, 604-607.

21.SONDAHL, M. R. et al. Somatic Embryogenesis and Plan Regeneration of cacao. Acta Hort. Republic of South África. 1993.

22. TAIZ, L., ZEIGER, E. Plant Physiology. 2 ed. Sunderland Massachusetts: s.n., 1998.

23.TISSERAT, B; ESAN, E Y MURASHIGE, T. Somatic embryogenesis in angiosperms. Hort Rev. 1.1979.

Recibido : Abril 13 de 2005

Aceptado: Julio 1 de 2005 